\title{
Coats plus syndrome: a rare cause of severe gastrointestinal tract bleeding in children - a case report
}

\author{
Selcen Bozkurt ${ }^{1 *}$ (D), Ayse Merve Usta², Nafiye Urganci², Nida Gulderen Kalay ${ }^{3}$, Gulsen Kose ${ }^{4}$
} and Evrim Ozmen ${ }^{5}$

\begin{abstract}
Background: Coats plus syndrome, cerebroretinal microangiopathy with calcifications and cysts, is a rare disease with autosomal recessive pattern occurring due to a mutation in CTC1, encoding conserved telomere maintenance component 1, gene. Besides retinal involvement, abnormalities in brain and osteopenia, serious life-threatening bleeding in gastrointestinal tract and portal hypertension can be observed.

Case presentation: A 6-year-old girl with Coats plus syndrome presented to the pediatric emergency department with vomiting blood and blood in stool. An upper and lower gastrointestinal endoscopy revealed esophageal varices and vascular telangiectasia in the pyloric antrum, duodenum, and colon. She received palliative care and the bleeding was stopped after receiving intravenous octreotide. She then was followed in the pediatric gastroenterology, neurology, and ophthalmology clinics. She was later hospitalized and admitted to the intensive care unit as she continued to have intermittent gastrointestinal system bleeding. She eventually died due to severe gastrointestinal system bleeding.
\end{abstract}

Conclusions: Coats plus syndrome can lead to life-threatening gastrointestinal bleeding and portal hypertension. As Coats plus syndrome is quite rare, there is little published data on this syndrome. This report presents a case of Coats plus syndrome as a rare cause of gastrointestinal bleeding and portal hypertension.

Keywords: Coats plus syndrome, Gastrointestinal bleeding, Portal hypertension, Octreotide, Leukocoria

\section{Background}

Coats plus syndrome, cerebroretinal microangiopathy with calcifications and cysts (CRMCC), is a rare disease with an autosomal recessive pattern caused by a mutation in the encoding conserved telomere maintenance component 1 (CTC1) gene. The CTC1 gene is located on chromosome 17p13.1 and plays an important role in telomere replication [1-3]. It is a multisystem disorder characterized by retinal telangiectasia and subretinal exudate, intracranial calcification, leukodystrophy, prenatal and postnatal growth retardation. In addition, parenchymal

*Correspondence: bozkurt.selcen@gmail.com

'Department of Pediatrics, Karadeniz Eregli State Hospital, Zonguldak, Turkey Full list of author information is available at the end of the article brain cysts, osteopenia with predisposition to fractures, serious life-threatening bleeding in gastrointestinal tract and portal hypertension can be observed in the patients with CRMCC [1-3]. In this case report, Coats plus syndrome, a rare cause of severe gastrointestinal bleeding and portal hypertension is presented.

\section{Case presentation}

A 6-year-old girl presented to the pediatric emergency department with the chief complaints of vomiting blood and blood in stool. Her mother reported that she noticed the blood in her daughter's stool three days ago and her daughter then started vomiting blood and the symptoms became worse dramatically. 


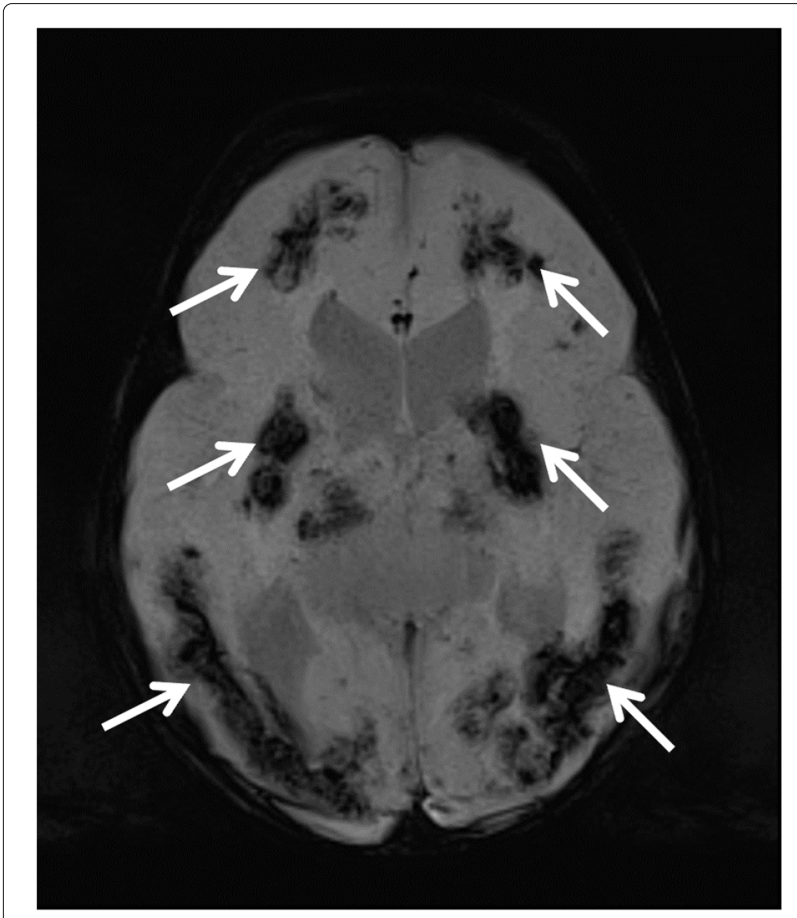

Fig. 1 Diffuse symmetric calcifications in MRI

The baby was delivered at 34 weeks gestation with cesarean section with intrauterine growth restriction (IUGR), hospitalized in a neonatal intensive care unit for 1 month and treated with laser photocoagulation due to the vision loss in the left eye. The cranial magnetic resonance imaging (MRI) was performed at the age of 6 months in a pediatrics neurology clinic due to convulsions and it revealed diffuse symmetric calcifications, changes suggesting hemorrhage, dilated lateral ventricles, septated cystic lesions in the area extending from the roof of the third ventricle to the lateral ventricle and also hemorrhage in the globe in left orbit (Figs. 1, 2 and 3). After further ophthalmoscopic tests, cranial findings and genetic tests, the patient was diagnosed with Coats plus syndrome.

Physical examination of the patient showed that the weight and height were below the 3rd percentile and mid-upper arm circumference $<115 \mathrm{~mm}$. The patient was ill-appearing. Her peak heart rate was $120 / \mathrm{min}$ and her blood pressure was $70 / 40 \mathrm{mmHg}$. Leukocoria and glaucoma were detected in left eye (Fig. 4). The patient had hypotonia and her muscle strength in bilateral lower and upper extremities was 3/5. The liver and the spleen were not palpable and the percussion over Traube's space produced dull sounds during the abdominal examination.

Laboratory test results were: hemoglobin $(\mathrm{Hb}): 6.5$ $\mathrm{gr} / \mathrm{dL}$, hematocrit (Hct): 21\%, thrombocyte count: 292000/mm3, white blood cell (WBC) count: $2010 / \mathrm{mm}^{3}$, international normalized ratio (INR): 1.3 , alanine aminotransferase (ALT): $113 \mathrm{U} / \mathrm{L}$, aspartate aminotransferase (AST): 115U/L, gamma-glutamyl transferase (GGT): 245 U/L, albumin: $3.21 \mathrm{gr} / \mathrm{dL}$. The metabolic studies did not show any abnormalities and the levels of viral markers, alpha 1 antitrypsin, alpha fetoprotein, ceruloplasmin, autoantibody and tissue transglutaminase were normal.

Abdominal ultrasonography showed linear echogenicity and heterogeneity in the liver. Abdominal doppler ultrasonography suggested portal hypertension. An upper and lower gastrointestinal endoscopy revealed folded vascular appearance reminiscent of esophageal varices, as well as vascular telangiectasia in the pyloric antrum, duodenum and colon (Fig. 5). A liver biopsy revealed portal fibrosis.

The patient was initially received nothing-by-mouth diet and intravenous (IV) proton pump inhibitors. The severe gastrointestinal bleeding of the patient was later stopped after receiving IV octreotide and erythrocyte transfusion. The patient kept being treated with

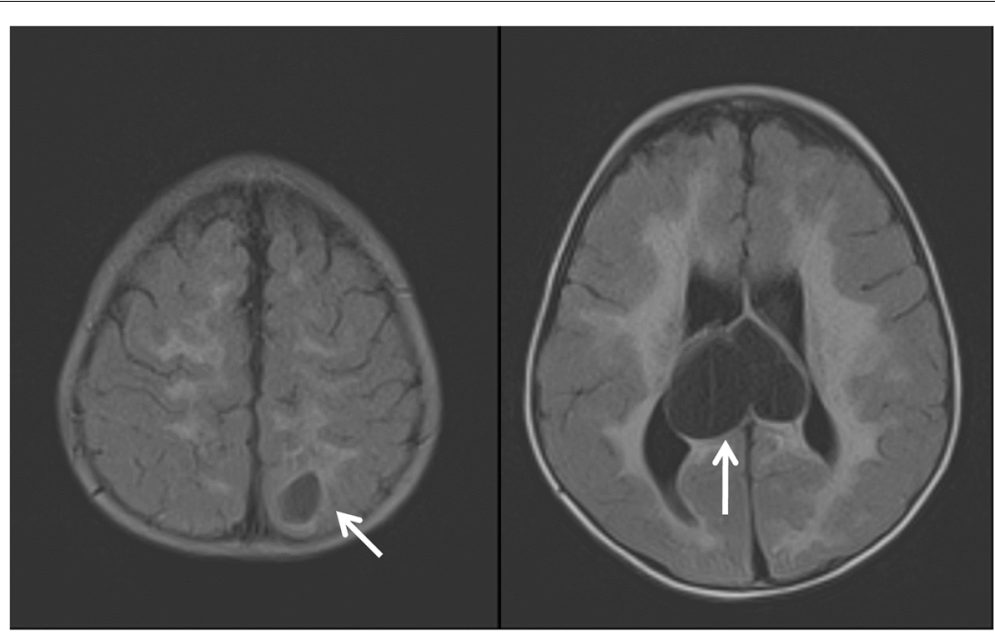

Fig. 2 Intracranial cysts in cranial MRI 


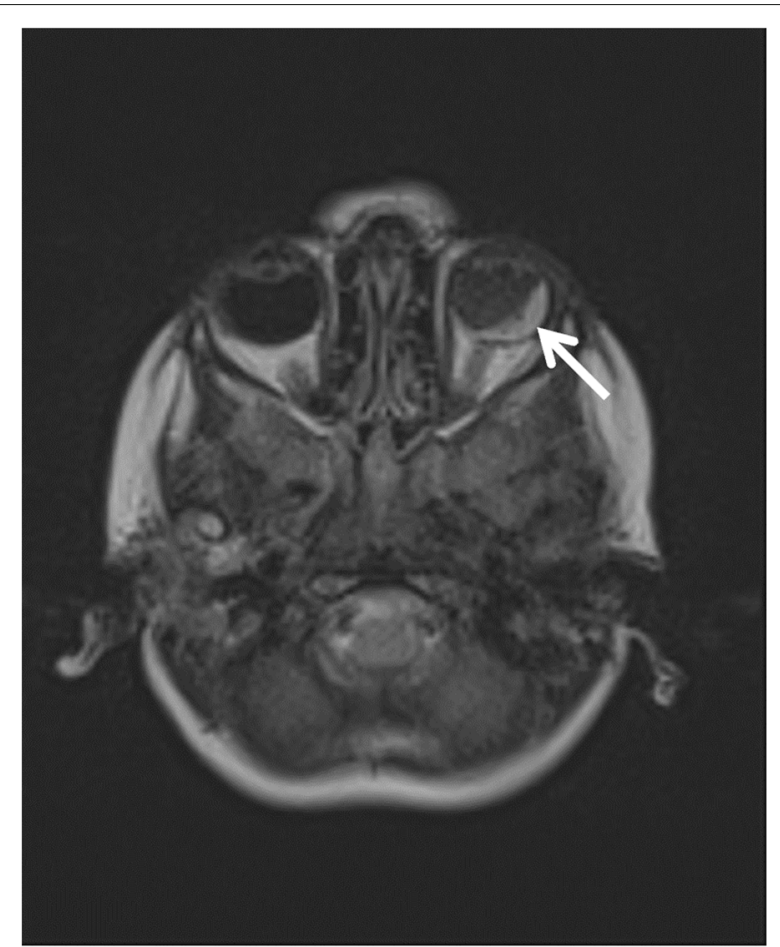

Fig. 3 Hemorrhage in left eye in cranial MRI

propranolol, ursodeoxycholic acid and anticonvulsant. The patient was followed in the pediatric gastroenterology, neurology, and eye clinics. She continued to have intermittent gastrointestinal system bleeding and had severe malnutrition; therefore, the patient was admitted to the emergency department and hospitalized multiple times. The patient was treated with tranexamic acid when she had mild bleeding and received IV octreotide when the bleeding was severe. The patient later was admitted to the intensive care unit due to multi-organ failure secondary to severe gastrointestinal system bleeding, and for

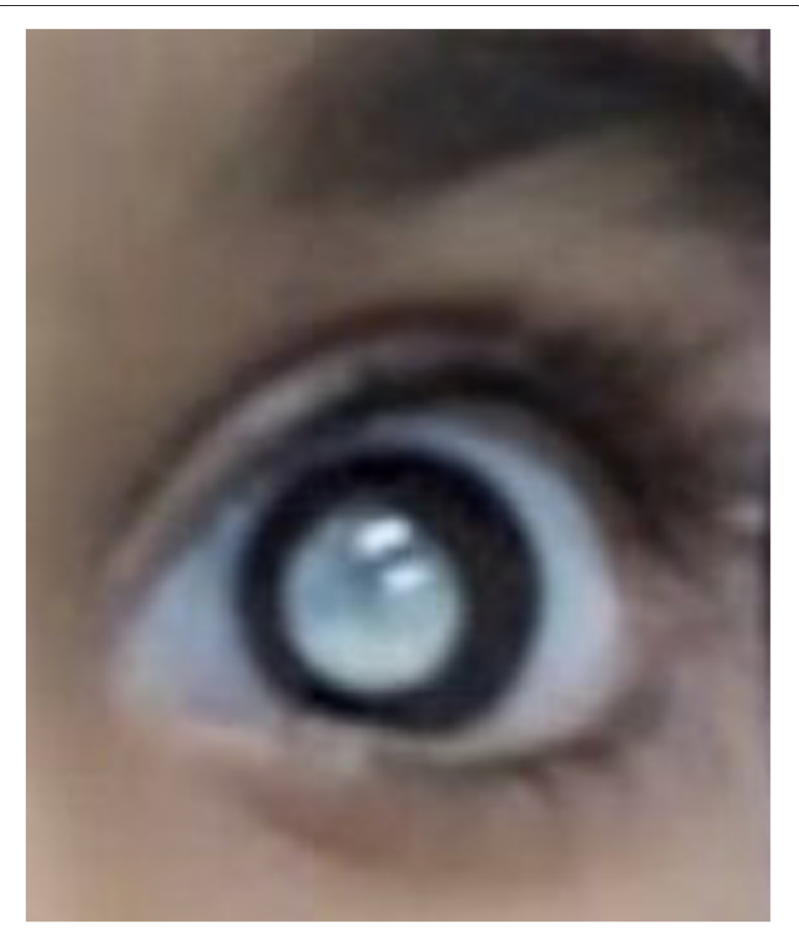

Fig. 4 Leukocoria in left eye

that reason an emergency endoscopy could not be performed. She received IV octreotide and erythrocyte transfusion again; however, her condition did not improve, and she eventually died.

\section{Discussion and conclusions}

CRMCC is a rare disease with autosomal recessive pattern occurring due to a mutation in CTC1 gene which is located on chromosome 17p13.1 region and responsible for telomere replication [1-3]. CRMCC can lead to a variety of symptoms including retinal involvement,

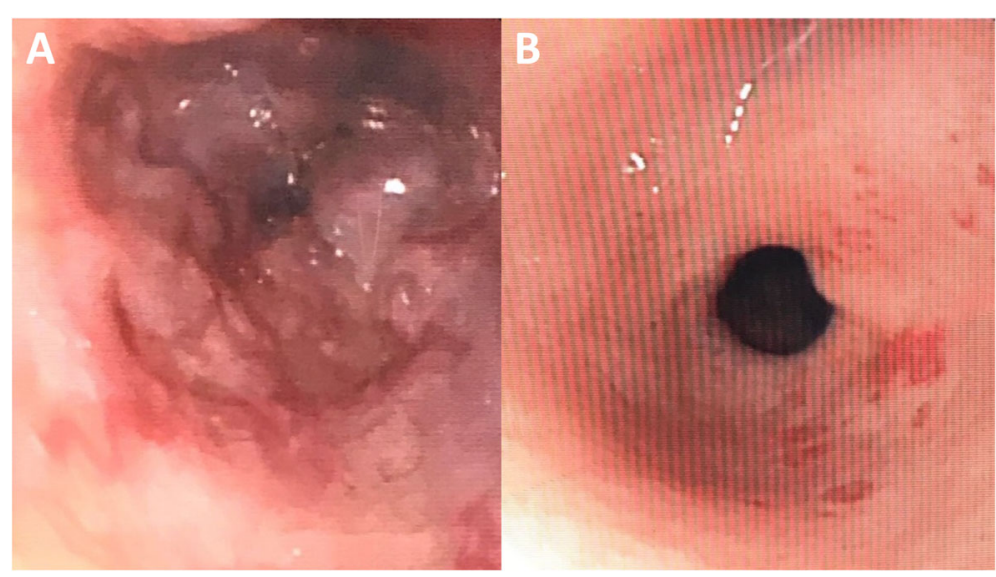

Fig. 5 Gastrointestinal endoscopy images A: Esophageal varices B: Vascular telangiectasia near pyloric antrum 
intracranial calcifications, leukodystrophy, restriction in prenatal and postnatal growth, changes in bone and skeletal system, osteopenia, portal hypertension and lifethreatening gastrointestinal system bleeding [1].

The patients with Coats plus syndrome are characterized by IUGR. IUGR is generally followed by restriction in prenatal and postnatal growth but there are cases with normal growth pattern [4]. Our patient was born with IUGR and the physical examination showed that the weight and the height were below 3rd percentile and midupper arm circumference $<115 \mathrm{~mm}$, which indicates severe malnutrition.

Ocular symptoms may occur with retinal telangiectasia, subretinal exudate, vitreous bleeding, angiomatous nodules, glaucoma, unilateral or bilateral blindness [4]. Neurologic symptoms can appear in different forms such as epilepsy, ataxia, spasticity, dystonia depending on the involved part of the brain [4]. The changes in brain tissue and signaling in brain alongside cysts and calcifications can be detected using Neuroradiological imaging of CRMCC [2]. At the age of 1 month, our patient was diagnosed with vision loss in her left eye and was treated with laser photocoagulation. There were leukocoria and glaucoma in the left eye. The cranial MRI was performed in the pediatrics neurology due to convulsions at 6 months of age and it showed diffuse symmetric calcifications, hemorrhage, dilated lateral ventricles, septated cystic lesions in the area extending from the roof of the third ventricle to the lateral ventricle and hemorrhage in the globe in left orbit.

Life-threatening symptoms such as gastrointestinal system bleeding and portal hypertension can be observed in patients with Coats plus syndrome. Liver failure and gastrointestinal bleeding play major roles in mortality and morbidity and inflammatory changes, abnormal vascularization, telangiectatic vessels can be detected in liver biopsy. [4-6]. In the current literature, embolization and hormonal therapy have been used to stop gastrointestinal bleeding with CRMCC[6-8]. Gastrointestinal endoscopies showed our patient had and esophageal varices and vascular telangiectasia throughout the gastrointestinal tract. In addition, a liver biopsy showed our patient had portal fibrosis. Initially, treatment with IV octreotide resolved the bleeding; however, the patient was later admitted to the intensive care unit and eventually died because of multi-organ failure secondary to severe gastrointestinal bleeding.

In summary, Coats plus syndrome can cause serious life-threatening gastrointestinal bleeding. There are only few reported cases and there is no established treatment approach for gastrointestinal bleeding with Coats plus syndrome [7]. This report presents a case of Coats plus syndrome as a rare cause of gastrointestinal bleeding and portal hypertension.

\begin{abstract}
Abbreviations
CRMCC: cerebroretinal microangiopathy with calcifications and cysts; CTC1: encoding conserved telomere maintenance component 1; IUGR: intrauterine growth restriction; $\mathrm{MRI}$ : magnetic resonance imaging; $\mathrm{Hb}$ : hemoglobin $\mathrm{Hct}$ : hematocrit WBC: white blood cell INR: international normalized ratio ALT: alanine aminotransferase AST: aspartate aminotransferase GGT: gamma-glutamyl transferase IV: intravenous
\end{abstract}

\section{Acknowledgements}

Not applicable.

\section{Authors' contributions}

SB wrote the case report. AMU, NU, GK provided patient care. AMU reviewed the report. NGK and EO assisted with the editing of the report, and they contributed to data collection, analysis, and interpretation. All authors read and approved the final version of the manuscript.

\section{Funding}

There was no funding for this study.

Availability of data and materials

The datasets used and/or analyzed during the current study are available from the corresponding author on reasonable request.

\section{Declarations}

Ethics approval and consent to participate

Not applicable.

\section{Consent for publication}

A written consent was obtained from the patient's mother for publication of this case report and accompanying images.

\section{Competing interests}

The authors declare that they have no competing interests.

\section{Author details}

${ }^{1}$ Department of Pediatrics, Karadeniz Eregli State Hospital, Zonguldak, Turkey. ${ }^{2}$ Department of Pediatric Gastroenterology, Sisli Hamidiye Etfal Training and Research Hospital, University of Health Sciences, Istanbul, Turkey. ${ }^{3}$ Department of Pediatrics, Sisli Hamidiye Etfal Training and Research Hospital, University of Health Sciences, Istanbul, Turkey. ${ }^{4}$ Department of Pediatric Neurology, Sisli Hamidiye Etfal Training and Research Hospital, University of Health Sciences, Istanbul, Turkey. ${ }^{5}$ Department of Pediatric Radiology, Sisli Hamidiye Etfal Training and Research Hospital, University of Health Sciences, Istanbul, Turkey.

Received: 17 October 2021 Accepted: 26 January 2022

Published online: 08 March 2022

\section{References}

1. Crow Y, McMenamin J, Haenggeli C-A, Hadley D, Tirupathi S, Treacy E, Zuberi S, Browne B, Tolmie J, Stephenson J. Coats' plus: a progressive familial syndrome of bilateral coats' disease, characteristic cerebral calcification, leukoencephalopathy, slow pre-and post-natal linear growth and defects of bone marrow and integument. Neuropediatrics. 2004;35(01):10-9.

2. Mansukhani S, Ho ML, Gavrilova RH, Mohney BG, Quiram PA, Brodsky MC. Cerebroretinal microangiopathy with calcifications and cysts (crmcc) or "coats plus": when peripheral retinal vasculature signals neurologic disease. J Am Assoc Pediatr Ophthalmol Strabismus. 2017;21(5):420-2.

3. Polvi A, Linnankivi T, Kivelä T, Herva R, Keating JP, Mäkitie O, Pareyson D, Vainionpää L, Lahtinen J, Hovatta I, et al. Mutations in ctc1, encoding the cts telomere maintenance complex component 1, cause cerebroretinal microangiopathy with calcifications and cysts. Am J Hum Genet. 2012;90(3):540-9.

4. Linnankivi T, Valanne L, Paetau A, Alafuzoff I, Hakumäki J, Kivelä T, Lönnqvist T, Mäkitie $O$, Pääkkönen L, Vainionpää L, et al. Cerebroretinal microangiopathy with calcifications and cysts. Neurology. 2006;67(8): $1437-43$ 
5. Briggs T, Abdel-Salam G, Balicki M, Baxter P, Bertini E, Bishop N, Browne B, Chitayat D, Chong W, Eid M, et al. Cerebroretinal microangiopathy with calcifications and cysts (crmcc). Am J Med Genet A. 2008;146(2):182-90.

6. Briggs T, Hubbard M, Hawkins C, Cole T, Livingston J, Crow Y, Pigott A. Treatment of gastrointestinal bleeding in a probable case of cerebroretinal microangiopathy with calcifications and cysts. Mol Syndromology. 2010;1(4):159-62.

7. Jeraq M, Armstrong V, Klimovich G, Rao KA, Byers P. Fatal gastrointestinal bleeding in a case report of coat's plus syndrome. Int I Surg Case Rep. 2020;66:233-5.

8. Passi GR, Shamim U, Rathore S, Joshi A, Mathur A, Parveen S, Sharma P, Crow YJ, Faruq M. An indian child with coats plus syndrome due to mutations in stn1. Am J Med Genet A. 2020;182(9):2139-44.

\section{Publisher's Note}

Springer Nature remains neutral with regard to jurisdictional claims in published maps and institutional affiliations.

- fast, convenient online submission

- thorough peer review by experienced researchers in your field

- rapid publication on acceptance

- support for research data, including large and complex data types

- gold Open Access which fosters wider collaboration and increased citations

- maximum visibility for your research: over $100 \mathrm{M}$ website views per year

At BMC, research is always in progress.

Learn more biomedcentral.com/submissions 